\title{
Seasonality of symptomatic bacterial urinary infections in women
}

\author{
JOHN E ANDERSON \\ From the Department of Family Medicine, Queen's University, Kingston, Ontario, Canada K7L 5E9
}

SUMMARY Bacterial infections of the female urinary tract (UTI) are a frequent clinical problem. A chance observation, supported by a one year survey reported from another country, suggested that UTI presented to the general practitioner more frequently in the summer. A retrospective survey, covering three consecutive years, was carried out to test this observation. The records of all women reported as attending this practice with a UTI showed that 213 culture positive episodes occurred in the third calendar quarter of each year. Edward's test for cyclic variation showed a significant peaking in August. These results indicate a definite seasonal fluctuation in the frequency with which symptomatic UTIs present to general practitioners in this practice. The clinical and epidemiological significance of this phenomenon remains to be determined.

Bacterial infections of the urinary tract (UTI) are a common problem in women. General practitioners have reported encounter rates of from eight to 17 per thousand registered patients. ${ }^{1-3}$ Surveys for asymptomatic UTI have estimated prevalence rates of $5-10 \%$ in populations of sexually active women. ${ }^{4}$ Despite the common nature of the problem, there remain gaps in our knowledge about it. From the epidemiological standpoint, the abrupt rise in frequency during late adolesence and early adulthood has been ascribed to sexual activity. ${ }^{5}$ Both Asscher and Rocha have concluded that race has no significant effect on prevalence rates, ${ }^{67}$ although Bailey has noted a high rate in Maori women. ${ }^{4}$ Increasing age seems associated with increased risk, independent of sexual activity and parity. ${ }^{6}$ Kunin has stated that neither the use of oral contraceptives nor different modes of menstrual hygiene "appear to affect the frequency of bacteriuria." 8

A chance observation in the practice at the Hotel Dieu Family Medicine Centre of Queen's University raised the possibility of a seasonal fluctuation in the frequency of UTI, with a peaking in the summer. This possibility was strengthened by similar findings in a one year study in Denmark. ${ }^{\circ}$ In contrast, peak rates in children have been reported to occur in the winter in both England ${ }^{10}$ and Finland. ${ }^{11}$

A retrospective review of patients records was undertaken to determine if this apparent fluctuation in the presentation of UTI was systematic or random. An assessment was also made of the accuracy of treatment decisions made before culture results were available. ${ }^{12}$

\section{Methods}

This centre houses the major teaching practice of the university's department of family medicine. The practice consists of 10 faculty members, each supervising one or two resident physicians at any one time. Except for the involvement of these residents, the clinical activities of the practice are similar to those of other family or general practices in Canada.

An encounter reporting system has been used to compile demographic and diagnostic information on patients attending the centre. A morbidity register has been developed with diagnostic data being classified by the International Classification of Health Problems in Primary Care (ICHPPC) ${ }^{13}$ This register was used to identify all female patients who had attended with a reported diagnosis of cystitis or UTI (ICHPPC code 595-) between 1 July 1976 and 30 June 1979. Their records were retrieved and reviewed by a research assistant using a standard abstraction form, recording age, date of presentation, presence or absence of urinary symptoms and physical signs, performance and results of microscopy and midstream urine culture, and, finally, antibiotic treatment.

Although ICHPPC does not have a separate rubric for chronic or recurrent urinary tract infection, the research assistant was instructed to exclude all 
Table 1 Distribution of the attending population during each of the study years. (Proportion of the specific annual population is shown in parentheses)

\begin{tabular}{|c|c|c|c|c|c|c|c|c|}
\hline \multirow[b]{3}{*}{ Year } & \multicolumn{8}{|l|}{ Age group } \\
\hline & \multicolumn{2}{|l|}{$0-14$} & \multicolumn{2}{|l|}{$15-44$} & \multicolumn{2}{|l|}{$\geqslant 45$} & \multicolumn{2}{|l|}{ Total } \\
\hline & $\begin{array}{r}\text { Female } \\
\%\end{array}$ & Male $\%$ & $\begin{array}{r}\text { Female } \\
\%\end{array}$ & $\begin{array}{r}\text { Male } \\
\%\end{array}$ & $\begin{array}{r}\text { Female } \\
\%\end{array}$ & Male $\%$ & $\begin{array}{r}\text { Female } \\
\%\end{array}$ & $\begin{array}{r}\text { Male } \\
\%\end{array}$ \\
\hline $\begin{array}{l}1976-7 \\
1977-8 \\
1978-9 \\
\text { Total }\end{array}$ & $\begin{array}{r}908(13.6) \\
940(12.6) \\
999(12.6) \\
2847(12.9)\end{array}$ & $\begin{array}{l}1028(15 \cdot 4) \\
1068(14 \cdot 3) \\
1122(14 \cdot 2) \\
3218(14 \cdot 6)\end{array}$ & $\begin{array}{l}1983(29 \cdot 7) \\
2408(32 \cdot 3) \\
2630(33 \cdot 2) \\
7021(31 \cdot 8)\end{array}$ & $\begin{array}{l}1208(18 \cdot 1) \\
1306(17 \cdot 5) \\
1295(16 \cdot 4) \\
3809(17 \cdot 3)\end{array}$ & $\begin{array}{r}923(13 \cdot 8) \\
1032(13 \cdot 8) \\
1146(14 \cdot 5) \\
3101(14 \cdot 1)\end{array}$ & $\begin{array}{r}634(9.5) \\
698(9.4) \\
727(9.2) \\
2059(9.3)\end{array}$ & $\begin{array}{r}3814(57 \cdot 1) \\
4380(58 \cdot 8) \\
4775(60 \cdot 3) \\
12969(58 \cdot 8)\end{array}$ & $\begin{array}{l}2870(42 \cdot 9) \\
3072(41 \cdot 2) \\
3144(39 \cdot 7) \\
9086(41 \cdot 2)\end{array}$ \\
\hline
\end{tabular}

patients who had such a diagnosis recorded in their files.

Urine samples for midstream culture and colony count are collected in the centre and transferred to the hospital laboratory in an adjacent building. Blood agar plates are used. The methods of collecting and plating did not change during the course of the study.

This report deals with episodes in which there was a recorded culture report showing 100000 or more identical organisms per $\mathrm{cc}$ and in which the patient's initial visit occurred between 1 July 1976 and 30 June 1979. These are referred to as culture positive episodes.

\section{Results}

Table 1 shows population attending the centre during each study year. Although the survey is limited to female patients, this table provides data on male patients to give a more complete picture of the practice. The age/sex distribution of the attending population remained quite consistent over the three years, despite a steady growth in size.

After exclusion of patients whose initial visit was before 1 July 1976, there were 660 episodes reported and correctly coded as UTI. Seven patient files could not be located, so the final sample consisted of 653 episodes. Urine culture reports were included in the records of 578 of these episodes; 239 of these cultures were reported as positive.

Table 2 shows the rate of culture positive episodes of UTI in the female attending population. Since there were so few culture positive episodes in those aged under 15, all further analyses were limited to those 212 episodes occurring in women aged 15 or more. The mean annual rate of culture positive UTI was 21.0 per 1000 attending in this age group. Ninety eight per cent of these episodes were symptomatic.

These 212 episodes occurred in 198 women. Seven women had two discrete episodes during the period surveyed, while three patients had three episodes. These repetitive episodes might have effected the hypothesis under study in only three instances. One
Table 2 Age/sex specific frequency (per 1000) of culture positive UTIs in attending female patients. (Number of cases appear in parentheses)

\begin{tabular}{lclll}
\hline \multicolumn{5}{c}{ Age group (years) } \\
\cline { 2 - 5 } Year & $0-14$ & $15-44$ & $\geqslant 45$ & Total \\
\hline $1976-7$ & $4 \cdot 1(4)$ & $20.7(41)$ & $21.7(20)$ & $17.0(65)$ \\
$1977-8$ & $9.6(9)$ & $20.3(49)$ & $24 \cdot 2(25)$ & $18.9(83)$ \\
$1978-9$ & $14.0(14)$ & $24 \cdot 2(63)$ & $12.2(14)$ & $19.3(91)$ \\
Mean annual & 9.5 & 21.8 & 19.0 & 18.4 \\
\hline
\end{tabular}

woman had two episodes in the first calendar quarter, but in two different years (1977 and 1989). Two other women each had two episodes arising in the same month, but different years (September 1976, 1978 and July 1977, 1978 respectively).

The expected and observed monthly frequencies of culture positive episodes were determined (fig 1). Although there were sporadic peaks in the frequency, there were also consistent systematic peaks in the warmer season of each of the three years. A comparison of the expected and observed quarterly encounter rates (fig 2 ) showed a consistent, cyclic, and systematic pattern over the survey period with peak rates being achieved in the third calendar quarter of each year.

The three year patient count, totalled by month, again showed a peaking of episodes in the warmer months (fig 3 ). The two patients with repeat episodes in the same month were counted only once each. Edward's test for cyclic variation ${ }^{14}$ was applied to these latter data and showed a statistically significant peaking in August $(p<0.025)$.

Physicians ordered urine cultures in $88.5 \%$ of the 579 reported episodes in women aged 15 or more: $41.2 \%$ of these cultures were reported as being positive. The proportion of episodes in which cultures were ordered and the proportion of cultures that were positive did not vary significantly between calendar quarters (tables 3 ). 


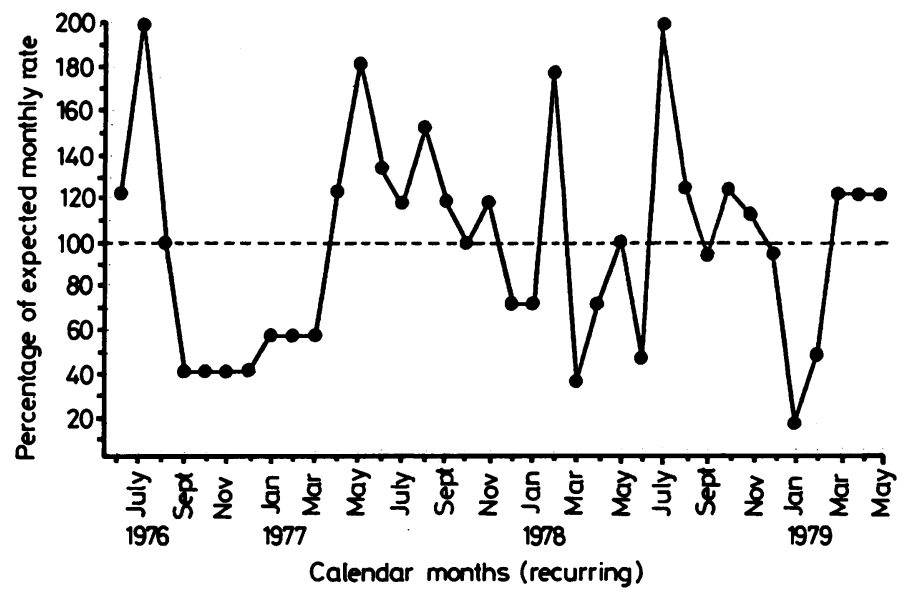

Fig 1 Relationship between expected and observed monthly rates of culture positive episodes of UTI in women aged 15 or more.

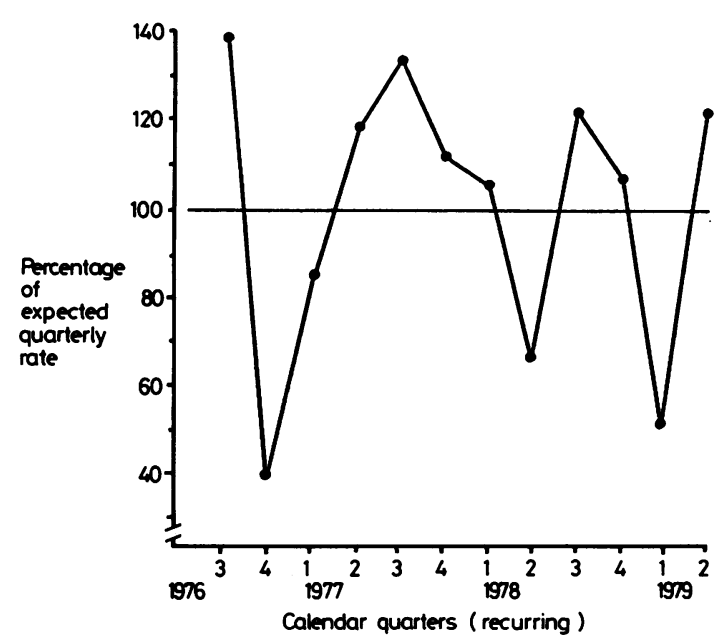

Fig 2 Relationship between expected and observed quarterly rates of culture positive episodes of UTI in attending female population aged 15 or more. (Three patients are represented twice in this figure-one in the third quarters of 1976 and 1978, one in the third quarters of 1977 and 1978, and one in the first quarters of 1977 and 1979.)

\section{Discussion}

The results of this survey indicated a seasonal variation in the frequency of symptomatic bacterial UTI in women in our practice. There is no evidence

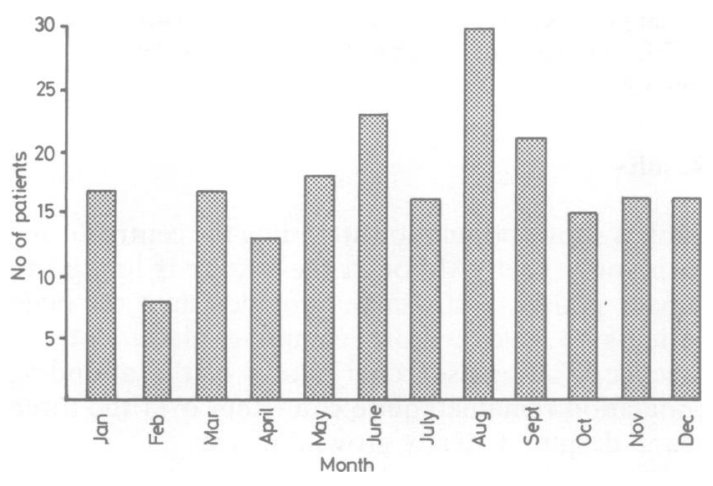

Fig 3 Three year total care count (on a monthly basis) of culture positive episodes of UTI in women aged 15 or more.

that urine specimens were processed differently at different times of the year. The physicians were constant in the proportion of reported episodes in which they ordered cultures and they were no more discriminating in ordering cultures in any one season. Patient selection of source of care may have created a bias. Presumably patients would select an alternate source of care, especially an emergency department, when their symptoms were more severe or there was a real or perceived delay before they could be seen in the practice, or a combination of these. There is no information with which the seasonality of symptom severity can be assessed, but evidence indicated that there was no effect from patients seeking other care 
Table 3 Frequency with which cultures were ordered in reported episodes of UTI and the frequency with which these cultures were reported as positive

\begin{tabular}{lccccc}
\hline & $\begin{array}{l}\text { Jan- } \\
\text { Mar }\end{array}$ & $\begin{array}{l}\text { Apr- } \\
\text { Jun }\end{array}$ & $\begin{array}{c}\text { Jul- } \\
\text { Sept }\end{array}$ & $\begin{array}{l}\text { Oct- } \\
\text { Dec }\end{array}$ & Total \\
\hline $\begin{array}{l}\text { No of reported } \\
\text { episodes }\end{array}$ & 119 & 137 & 182 & 141 & 579 \\
$\begin{array}{l}\text { Proportion in which } \\
\text { cultures were } \\
\text { ordered (\%) }\end{array}$ & 90.8 & 88.3 & 89.0 & 89.4 & 89.3 \\
$\begin{array}{l}\text { Proportion of } \\
\text { cultures reported } \\
\text { as positive (\%) }\end{array}$ & 38.0 & 46.3 & 42.0 & 38.1 & 41.2 \\
\hline
\end{tabular}

because of delays in our practice. Thus these results probably reflect accurately the frequency of symptomatic bacterial UTI in women in this practice population.

Several reasons can be postulated for this seasonality in UTI: the hotter weather may induce relative dehydration which, in turn, may lead to more concentrated urine and less frequent voiding; swimming in natural (and potentially contaminated) bodies of water is most frequent in the third quarter; the hot weather may lead to a moisture perineum which could facilitate bacterial transfer from the rectum to the urethra. The incidence of urinary cystitis in women cannot, however, be discussed without consideration of the role of sexual intercourse.

Interestingly, there have been several reports of peak rates of sexually transmitted disease (STD) occurring at the same time of year. The incidence of gonorrhea is higher in Canada in the summer. ${ }^{15}$ Peak rates for other STD, including gonorrhea, nonspecific urethritis, and genital scabies have been reported to occur at the same time in Scotland, Germany, and the United States. ${ }^{16-18}$

It is tempting to suggest that the seasonal and coincidental fluctuations in the incidence of both UTI and STD are related to a higher frequency of sexual intercourse during the third calendar quarter. Association of the seasonal pattern of UTI with sexual activity would also explain the difference between the summer peaking in adults and the winter peaking described in children. ${ }^{1011}$

The probability of a simultaneous peaking in UTI and sexual activity is re-enforced by other evidence as well. Sales of over the counter contraceptives have been reported to be highest at this time of year. ${ }^{19}$ Similarly, patterns of conception, coital activity of married couples, frequency of reported rapes,${ }^{18}$ and the sexual activity of young men ${ }^{20}$ have all been reported to peak in the the summer months. (Parkes's somewhat caustic comment is worth repeating: "After all this, therefore, we arrive at the platitudinous conclusion that conceptions are most frequent when people are most festive and carefree"). ${ }^{19}$

Although there is evidence that the highest frequencies of sexual activity and UTI occur during the same calendar quarter, there is no solid evidence that the association is causal rather than factitious or casual. It has been suggested that the low rates of some STD in winter may result from the protective or curative effects of antibiotics prescribed for respiratory infection during the same season. ${ }^{21}$ Possibly the results obtained in this study of UTI have a similar iatrogenic basis. It is also possible that there is some circannual variation in host defence mechanism that may result in a higher risk of infection during the warmer season of the year.

Completely aside from conjectural questions of causation, it must be emphasised that the results of this survey may not be widely generalisable. The nature of Canada's health care system is such that patients may have attended other physicians or hospital emergency department at different rates during different periods of the year. Additional studies are required to determine if these results can be replicated in other settings. Further, the aetiological and clinical significance of the current findings are uncertain. It would be necessary to determine if there is any seasonal variation in the frequency with which women experience urinary symptoms and if the diseases underlying these symptoms have a constant or fluctuating frequency throughout the year. Among other things, it is possible that bacterial UTI has a constant frequency throughout the year but is more likely to be symptomatic in the warmer months.

This project was supported by a grant from the Physicians' Services Incorporated Foundation.

\section{References}

${ }^{1}$ Fry J, Dillane JB, Joiner CL, Williams JD. Acute urinary infections. Lancet 1962; i: 1318-21.

${ }^{2}$ Mond NC, Percival A, Williams JD, Brumfitt W. Diagnosis and treatment of urinary tract infections and general practice. Lancet 1965 ; i: 514-6.

${ }^{3}$ Loudon ISL, Greenhalgh GP. Urinary tract infections in general practice. Lancet 1962; ii: 1246-8.

${ }^{4}$ Bailey RR. Urinary tract infection revisited. NZ Med J 1973; 77: 69-74.

${ }^{5}$ Stamey TA. Urinary infections in women. In: Hamilton E Hartwell Harrison J, Gittes RF, Perlmutter AD, Stamey TA, Walsh P. Campbell's urology. Philadelphia: W B Saunders 1978.

${ }^{6}$ Asscher AW. Symptomless bacteriuria. In: Williams DI, Chishold GD, eds. Scientific foundations of urology. London: William Heinemann Medical Books Ltd, 1976. 
${ }^{7}$ Rocha $\mathrm{H}$. Epidemiology of urinary tract infections. In: Kaye D, ed. Urinary tract infection and its management. Saint Louis: C V Mosby Co, 1972.

${ }^{8} \mathrm{Kunin}$ CM. Detection, prevention and management of urinary tract infections. Philadelphia: Lea \& Febiger, 1974.

${ }^{9}$ Steensberg J, Bartels ED, Bay-Nielsen H, Fane E, Hede T. Epidemiology of urinary tract diseases in general practice. Br Med J 1969; iv; 390-4.

${ }^{10}$ Stansfield JM. Clinical observation relating to incidence and aetiology of urinary tract infections in children. $\mathrm{Br}$ Med J 1966; i: 631-5.

${ }^{11}$ Elo J, Sarna S, Tallgren LG. Seasonal variable in the occurrence of urinary tract infections among children in an urban area in Finland. Ann Clin Res 1979; 11: 101-6.

${ }^{12}$ Anderson JE. Initial treatment decisions in urinary tract infection. Canadian Family Physician 1981; 27: 190912.

${ }^{13}$ International classification of health problems in primary care. Chicago: American Hospital Association, 1975.

${ }^{14}$ Edwards $\mathrm{JH}$. The recognition and estimation of cyclic trends. Ann Hum Genet 1961; 25: 83-6.

${ }^{15}$ Statistics Canada, Health Division. Annual report of notifiable diseases (82-210). Ottawa: 1978.
${ }^{16}$ Schofield CBS. Seasonal variations in the reported incidence of sexually transmitted diseases in Scotland (1972-6). Br J Vener Dis 1979; 55: 218-22.

${ }^{17}$ Wright RA, Judson FN. Relative and seasonal incidences of the sexually transmitted diseases. $\mathrm{Br} J$ Vener Dis 1978; 54: 433-40.

${ }^{18}$ Smolensky MH. Chronobiological aspects of the epidemiology of human reproductions and fertility:, In: Ortavant R, Reinberg A, eds. Rythmes et reproduction. Paris: Masson, 1980.

${ }^{19}$ Parkes AS. Seasonal variation in human sexual activity. Eugenics Society Symposium 1968; 4: 128-45.

${ }^{20}$ Reinberg A, Lagoguey M. Circadian and circannual rhythms in sexual activity and plasma hormones (FSH,LH, testosterone) of five human males. Arch Sex Behav 1978; 7: 13-30.

${ }^{21}$ Reynolds GH, Zaidi AA, Thornsberry C, et al. The national gonorrhea therapy monitoring study: II. Trends and seasonality of antibiotic resistance of neisseria gonorrhoeae. Journal of Sexually Transmitted Diseases 1979; 6, suppl Apr-Jun: 103-11. 